\title{
Efficacy and Safety of Baclofen for Treatment of Alcohol Dependence: An Updated Meta-Analysis and Meta-Regression Study
}

\author{
W. PHIMARN*, P. CHAMNANJIT, W. ANUNWORAPUNYA, K. SARAMUNEE, B. SUNGTHONG \\ Social Pharmacy Research Unit, Faculty of Pharmacy, Mahasarakham University, Maha Sarakham 44150, Thailand
}

Phimarn et al.: Meta-Analysis of Baclofen for Treatment of Alcohol Dependence

\begin{abstract}
Baclofen is increasingly used for alcohol dependence treatment but its use remains controversial. Therefore, this study aimed to assess the efficacy and safety of baclofen use on alcohol dependence. This is systematic review and meta-analysis of randomized controlled trials. PubMed, Science Direct, Scopus and Thai databases were systematically searched. Randomized controlled trials investigating efficacy and safety of baclofen on alcohol dependence were included. Study selection, data extraction and quality assessment were performed independently by two reviewers. The clinical therapeutic efficacy and adverse events of baclofen were assessed and were pooled using a random-effects model. Heterogeneity was assessed by $I^{2}$ and chi-squared test. Sixteen studies with 1539 alcohol dependence patients were included. Baclofen increased risk of abstinence (risk ratio $=1.32 ; 95 \%$ confidence interval: $1.12,1.55 ; p=0.0006$ ) and abstinence duration (standard mean difference $=1.07 \mathrm{~d}(95 \%$ confidence interval: $0.13,2.01 ; p=0.04)$ significantly. Moreover, baclofen significantly decreased heavy drinking days (standard mean difference=-1.14 d; $95 \%$

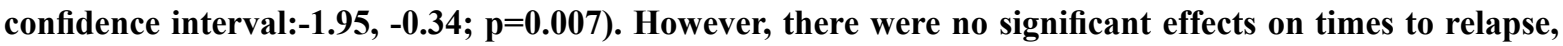
craving and number of alcohol drinks. No serious adverse event associated with baclofen was reported during treatments. The meta-regression found baclofen dose was significantly associated with craving. This meta-analysis indicated that baclofen treatment in alcohol dependence patients is associated with better outcomes in risk of abstinence, abstinence duration and heavy drinking days. However, larger welldesigned studies are required to confirm these conclusions.
\end{abstract}

Key words: Baclofen, alcohol dependence, meta-analysis, randomized controlled trials

Excessive alcohol consumption has been associated with non-communicable diseases that include liver disease, cancer and cardiovascular disease. Globally, alcohol use disorder is associated with negative health effects. Every year, nearly 3 million people die from complications related to alcohol use disorder ${ }^{[1]}$. Approximately $5 \%-10 \%$ of heavy and dependent drinkers are characterized as having Alcohol Dependence $(\mathrm{AD})^{[2]}$. Diagnostic and Statistical Manual of Mental Disorders (DSM)-IV defined AD as behavior that results in significant harm to health caused by at least three out of seven target conditions occurring within a 12 mo period. In 2013, AD was combined with alcohol abuse disorder in the DSM-V ${ }^{[3]}$.

$\mathrm{AD}$ is a serious health problem that reflects a chronic disease condition ${ }^{[4,5]}$. AD is a continued and increasing pattern of alcohol consumption that is often associated with deleterious physical and psychological

*Address for correspondence

E-mail: wiraphol.p@msu.ac.th

January-February 2022 consequences $^{[6]}$. The reported prevalence of $\mathrm{AD}$ in the world ranges from $8 \%-36 \%$ depending on the target population $^{[7]}$. The harmful health effects of alcohol abuse have been recognized as a significant risk factor for morbidity and mortality ${ }^{[8]}$.

Alcohol stimulates release of dopamine from neurons in the Ventral Tegmental Area (VTA), leading to inhibition of GABAergic neurotransmission ${ }^{[9]}$. Baclofen, a presynaptic GABA-B receptor agonist, acts to suppress activity of cortico-mesolimbic dopamine neurons ${ }^{[10]}$. Results from several animal studies suggest that baclofen reduces voluntary alcohol intake ${ }^{[11]}$.

This is an open access article distributed under the terms of the Creative Commons Attribution-NonCommercial-ShareAlike 3.0 License, which allows others to remix, tweak, and build upon the work non-commercially, as long as the author is credited and the new creations are licensed under the identical terms

Accepted 03 February 2022

Revised 19 April 2021

Received 09 December 2020 Indian J Pharm Sci 2022;84(1):137-149 
Baclofen reduces anxiety and other symptoms associated with alcohol withdrawa ${ }^{[12]}$. Baclofen is also used for $\mathrm{AD}$ treatment due to its purported action on GABA-B receptors, which are expressed throughout the limbic system. Baclofen can inhibit glutamate and aspartate release from nerve terminals and decrease serotonin-, noradrenaline-, and dopamine-mediated $\operatorname{activities}^{[13]}$. Baclofen is hypothesized to act via these different mechanisms to reduce alcohol withdrawal and anxiety ${ }^{[14]}$.

A previous meta-analysis ${ }^{[15]}$ demonstrated that baclofen administration did not increase the risk of abstinence or decrease the number of drinking days. Other studies ${ }^{[16,17]}$ have reported positive effects on risk of abstinence and times to relapse with no effect on percentage of days of abstinence. These inconsistent results may be due to differences in study design, the small number of participants, differences in study populations, duration of $\mathrm{AD}$, intervention periods, or differences in the dose of baclofen administered. In recent years, there have been updated published Randomized Controlled Trials (RCTs) of the effect of baclofen on AD. Previous metaanalyses ${ }^{[15,17]}$ also lacked meta-regression analysis, a tool of which can identify association between dosing and primary outcomes. In order to provide a comprehensive and quantitative synthesis of evidence from all RCTs, we performed an updated meta-analysis to evaluate the effect of baclofen on patients with AD.

\section{MATERIALS AND METHODS}

A systematic review and meta-analysis of RCTs was undertaken following the guidelines for Preferred Reporting Items for Systematic review and MetaAnalysis (PRISMA) ${ }^{[18]}$. All reports of RCTs of baclofen on alcohol dependence were identified through a systematic literature search of PubMed, Science Direct, Scopus and the Thai Citation Index (TCI). A historical search was also performed using reference lists of related reviews and original articles. The bibliographic databases were searched from their respective inceptions to 28 February 2020. The following Medical Subject Headings (MeSH) terms were used: Baclofen, Alcohol, Alcohol dependence, Alcohol use disorder (AUD), Abstinence, Craving, RCTs study, Alcoholism, detoxication, withdrawal. No language restriction was imposed.

\section{Study selection:}

For a study to be included in the meta-analysis, it had to be an RCT comparing baclofen to placebo or to no alcohol dependence treatment; reporting outcome measures in terms of abstinence, craving, heavy drinking days, and times to relapse; providing sufficient information on outcomes at baseline or at the end of follow up in each group. Criteria for excluded studies for this review were lack of sufficient information on baseline or at the end of studies and conference abstracts. Two authors independently reviewed all articles and a third author arbitrated any discrepancies including the studies in the meta-analysis.

\section{Data extraction:}

The data from individual studies were abstracted. Data were extracted using a standardized form. The data records included study design, the year of publication, country of origin, patient characteristic, sample size, duration of treatment, dose of baclofen, alcohol consumption level and outcome measurements.

\section{Quality assessment:}

A score was assigned to each publication based on criteria from Jadad et al. ${ }^{[19]}$, which was used to assess the quality of the included trial. Scores had a possible range from zero to five; a cutoff at two was used to identify studies of high versus low quality. Studies with a score of 2 points or less were classified as low quality. Studies with a score of 3 or more were classified as high quality. The risk of bias was evaluated using the Cochrane risk of bias 2.0 tool $^{[20]}$ which contained 5 domains bias arising from the randomization process, bias due to deviations from intended interventions, bias due to missing outcome data, bias in measurement of the outcome and bias in selection of the reported result. The overall risk of bias for each study was classified as either low, unclear, or high.

\section{Statistical analysis:}

The primary outcomes were risk of abstinence, abstinence duration, heavy drinking days, times to relapse, craving and number of drinking days. The secondary outcomes included Adverse Events (AEs) and liver function. If a recruited study reported the risk of abstinence as percent abstinence, then we calculated the results as the number of participants exhibiting abstinence. Pooled effects were calculated and stratified according to outcomes data. Summary statistics of dichotomous outcomes were expressed as a Risk Ratio (RR) with $95 \%$ Confidence Interval (CI), whereas summary statistics of continuous outcomes were expressed as Standard Mean Difference (SMD). Statistical heterogeneity between studies was assessed 
using the chi-squared test and $\mathrm{I}^{2}$. Tests for heterogeneity were considered significantly different when $p<0.05$ and substantial heterogeneity was represented by $\mathrm{I}^{2}$ of $50 \%$ or more ${ }^{[21]}$. If there was evidence of high heterogeneity, we attempted to determine the source by performing subgroup analyses when possible. Publication bias was assessed using Egger weighted regression statistics and a visual inspection of funnel plots $^{[22,23]}$. The Dersimonian and Laird random-effects model ${ }^{[24]}$ was employed for all analyses.

\section{Sensitivity and subgroup analysis:}

To ensure robustness of results, sensitivity analysis was performed by using fixed effect models ${ }^{[25]}$, including the one-study removal (leave-one-out) approach ${ }^{[26]}$. In addition, we conducted subgroup analyses based on the dose of baclofen, duration of treatments and risk associated with a specified alcohol consumption level[ ${ }^{[27]}$.

\section{Meta-regression:}

Meta-regression was employed to evaluate associations between the effect size and potential moderator variables, which included dosage and duration of baclofen supplementation. We performed a weighted fixed-effect meta-regression using the unrestricted maximum likelihood model.

\section{RESULTS AND DISCUSSION}

The trial flow is summarized in fig. 1. There were 520 clinical trials identified through the systematic search, with most studies published in English. After first level screening, 377 studies were excluded because they were either duplicate studies $(n=345)$ or not RCTs $(n=32)$. Another 117 trials were excluded as they were not relevant to the current analysis. Five additional studies were excluded because they were systematic reviews and meta-analyses and three studies were excluded because they are not related to interred outcomes. Sixteen RCTs were subjected to detailed analysis as they met all inclusion criteria.

Table 1 shows the characteristics of the sixteen studies $^{[28-43]}$. The total number of patients with AD was 1539. The included studies were published between 2002 and 2018. Follow-up durations ranged from $4 \mathrm{w}$ to $12 \mathrm{mo}$. All of the included articles used baclofen at doses between 30 and $300 \mathrm{mg} / \mathrm{d}$. In most of the studies, participants reported being $\mathrm{AD}$ for more than $10 \mathrm{y}$. All of the studies were designed as RCTs. Six studies ${ }^{[28,30,31,35,40,42]}$ earned a Jadad score of $5 / 5$. Four studies were conducted in Italy ${ }^{[28-30,36]}$, three in the USA ${ }^{[32,33,37]}$, two in Australia ${ }^{[39,40]}$, and two in France ${ }^{[34,42]}$. One trial each was performed in Israel ${ }^{[43]}$, Germany $^{[41]}$, Netherlands ${ }^{[31]}$, Russia ${ }^{[35]}$ and Thailand ${ }^{[38]}$.

Based on Cochrane's risk of bias criteria, all of the studies were rated as having a low risk of bias. All studies quality values indicated dependence on three domains: random sequence generation, allocation concealment and blinding of participants. One of sixteen ${ }^{[34]}$ was rated as having an unclear risk of bias in random sequence generation and allocation concealment domain (fig. 2).

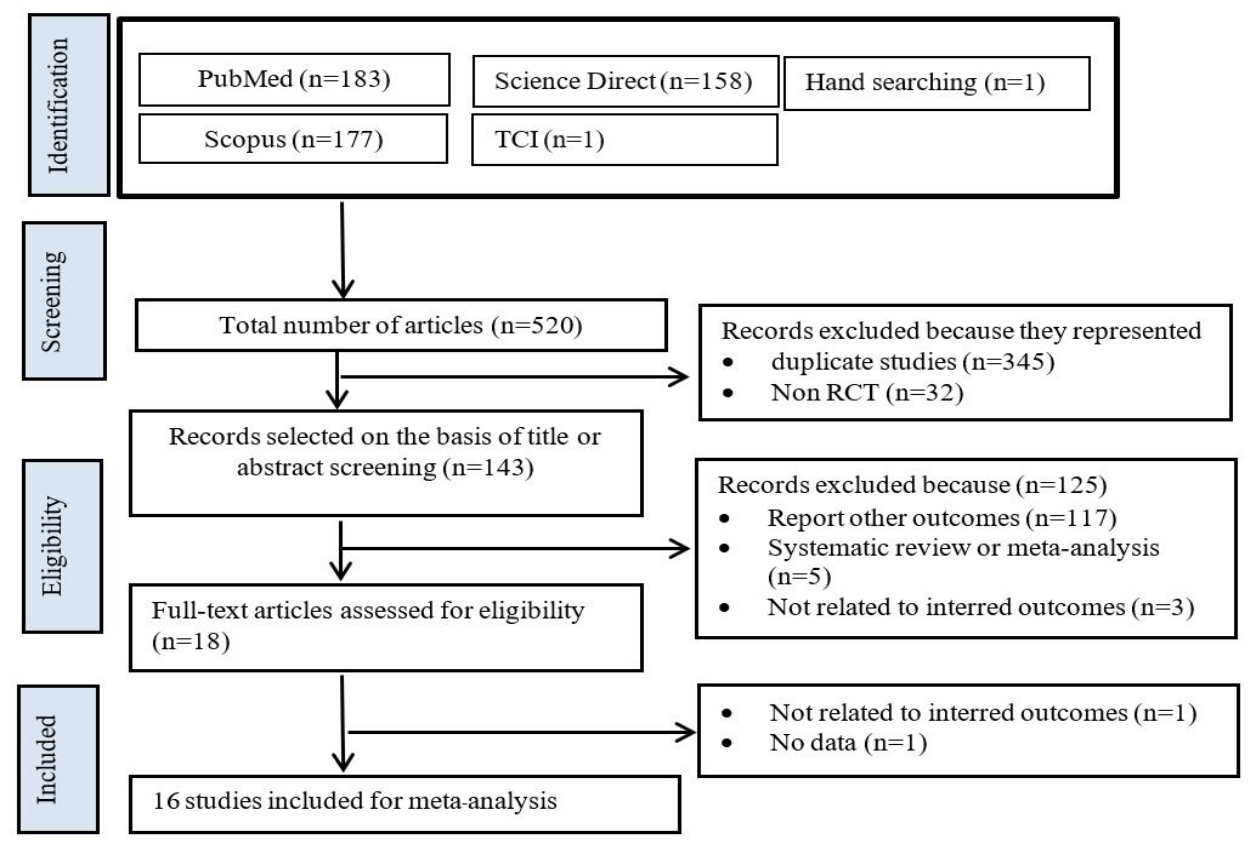

Fig. 1: A PRISMA flow diagram describing the selection process for identifying included studies. 
TABLE 1: CHARACTERISTICS OF INCLUDED STUDIES

\begin{tabular}{|c|c|c|c|c|c|c|c|c|}
\hline Authors (y) & $\mathbf{N}$ & Country & $\begin{array}{l}\text { Mean } \\
\text { age (y) }\end{array}$ & $\begin{array}{c}\text { Alcohol } \\
\text { consumption }\end{array}$ & $\begin{array}{c}\text { Baclofen } \\
\text { (Dose) }\end{array}$ & Duration & Outcomes & $\begin{array}{l}\text { Jadad } \\
\text { score }\end{array}$ \\
\hline Addolorato et al..$^{[28]}$ & 20 & Italy & 47.3 & $141.5 \mathrm{~g} / \mathrm{d}$ & $30 \mathrm{mg} / \mathrm{d}$ & $4 w$ & Number of drinking days & 5 \\
\hline Addolorato et al. ${ }^{[29]}$ & 42 & Italy & 49.25 & N/A & $30 \mathrm{mg} / \mathrm{d}$ & $4 w$ & $\begin{array}{c}\text { Risk of abstinence, abstinence } \\
\text { duration, times to relapse, } \\
\text { adverse effects }\end{array}$ & 4 \\
\hline Garbutt et al. ${ }^{[32]}$ & 40 & USA & 48.9 & $71 \mathrm{~g} / \mathrm{d}$ & $30 \mathrm{mg} / \mathrm{d}$ & $12 \mathrm{w}$ & $\begin{array}{l}\text { Risk of abstinence, abstinence } \\
\text { duration, number of drinking } \\
\text { days, craving, adverse effects }\end{array}$ & 3 \\
\hline Addolorato et al. ${ }^{[30]}$ & 28 & Italy & 46.3 & $\mathrm{~N} / \mathrm{A}$ & $\begin{array}{c}30 \mathrm{mg} / \mathrm{d} \text { and } \\
60 \mathrm{mg} / \mathrm{d}\end{array}$ & $12 \mathrm{w}$ & $\begin{array}{c}\text { Number of drinking days, } \\
\text { adverse effects }\end{array}$ & 5 \\
\hline Leggio et al. ${ }^{[36]}$ & 12 & Italy & 50.25 & $185 \mathrm{~g} / \mathrm{d}$ & $30 \mathrm{mg} / \mathrm{d}$ & $12 \mathrm{w}$ & $\begin{array}{l}\text { Risk of abstinence, adverse } \\
\text { effects }\end{array}$ & 4 \\
\hline Morley et al. ${ }^{[39]}$ & 90 & Australia & 46.83 & $154 \mathrm{~g} / \mathrm{d}$ & $30 \mathrm{mg} / \mathrm{d}$ & $12 \mathrm{w}$ & $\begin{array}{l}\text { Number of drinking days, times } \\
\text { to relapse, adverse effects }\end{array}$ & 4 \\
\hline Leggio et al. ${ }^{[37]}$ & 30 & USA & 46.3 & N/A & $80 \mathrm{mg} / \mathrm{d}$ & $12 \mathrm{w}$ & Risk of abstinence & 4 \\
\hline Ponizovsky et al. ${ }^{[43]}$ & 64 & Israel & 43.65 & $78 \mathrm{~g} / \mathrm{d}$ & $50 \mathrm{mg} / \mathrm{d}$ & $12 \mathrm{w}$ & $\begin{array}{l}\text { Abstinence duration, number } \\
\text { of drinking days }\end{array}$ & 4 \\
\hline Müller et al. ${ }^{[41]}$ & 56 & Germany & 46.5 & $198.7 \mathrm{~g} / \mathrm{d}$ & $30-270 \mathrm{mg} / \mathrm{d}$ & $24 w$ & $\begin{array}{l}\text { Risk of abstinence, abstinence } \\
\text { duration, adverse effects }\end{array}$ & 4 \\
\hline Beraha et al..$^{[31]}$ & 151 & Netherlands & 44.8 & $139.75 \mathrm{~g} / \mathrm{d}$ & $\begin{array}{l}30-60 \mathrm{mg} / \mathrm{d} \\
270 \mathrm{mg} / \mathrm{d}\end{array}$ & $16 w$ & $\begin{array}{l}\text { Risk of abstinence, abstinence } \\
\text { duration, craving, adverse } \\
\text { effects }\end{array}$ & 5 \\
\hline Mitmanochai et al. ${ }^{[38]}$ & 116 & Thailand & 43.5 & $143 \mathrm{~g} / \mathrm{d}$ & $30 \mathrm{mg} / \mathrm{d}$ & $14 w$ & Risk of abstinence & 4 \\
\hline Jaury et al. ${ }^{[34]}$ & 254 & France & 57.5 & $128.5 \mathrm{~g} / \mathrm{d}$ & $300 \mathrm{mg} / \mathrm{d}$ & $12 \mathrm{mo}$ & Risk of abstinence & 3 \\
\hline Krupitskii et al. ${ }^{[35]}$ & 32 & Russia & 45 & $\mathrm{~N} / \mathrm{A}$ & $50 \mathrm{mg} / \mathrm{d}$ & $12 \mathrm{w}$ & Number of drinking days & 5 \\
\hline Hauser et al. ${ }^{[33]}$ & 180 & USA & 57 & $70 \mathrm{~g} / \mathrm{d}$ & $30 \mathrm{mg} / \mathrm{d}$ & $12 \mathrm{w}$ & $\begin{array}{l}\text { Risk of abstinence, abstinence } \\
\text { duration, adverse effects }\end{array}$ & 4 \\
\hline Reynaud et al. ${ }^{[42]}$ & 320 & France & 49.4 & $94.55 \mathrm{~g} / \mathrm{d}$ & 180. $\mathrm{mg} / \mathrm{d}$ & $26 w$ & $\begin{array}{l}\text { Risk of abstinence, number of } \\
\text { drinking days, times to relapse, } \\
\text { adverse effect }\end{array}$ & 5 \\
\hline Morley et al. ${ }^{[40]}$ & 104 & Australia & 48.38 & $150 \mathrm{~g} / \mathrm{d}$ & $\begin{array}{l}30 \mathrm{mg} / \mathrm{d} \\
75 \mathrm{mg} / \mathrm{d}\end{array}$ & $12 \mathrm{w}$ & $\begin{array}{l}\text { Risk of abstinence, abstinence } \\
\text { duration, number of drinking } \\
\text { days, adverse effects }\end{array}$ & 5 \\
\hline
\end{tabular}

Note: N/A: not available; g: gram; mg: milligram; N: number of participants

The Jadad score for all the studies ranged from 3 to 5 to total of five scores.

The AD status of 1284 patients was determined in thirteen arm trials from 11 studies of baclofen against placebo ${ }^{[28,29,31-34,37,38,40-42]}$. The results were not significantly heterogeneous $\left(\mathrm{I}^{2}=0.8 \% ; \mathrm{p}=0.438\right)$. Baclofen was superior to placebo regarding its ability to increase risk of abstinence. The pooled risk ratio for risk of abstinence was 1.32 (95\% CI: 1.12, 1.55; $\mathrm{p}=0.0006)$ (fig. 3A).

Poolable data was provided by 567 alcohol dependent patients enrolled in eight trials of baclofen against placebo $^{[29,31-33,36,40,41,43]}$. The results were significantly heterogeneous $\left(I^{2}=95.9 \% ; p=0.001\right)$. The results indicated that baclofen was more effective than placebo in increasing abstinence duration. The pooled SMD was $1.07 \mathrm{~d}$ (95\% CI 0.13, 2.01; $\mathrm{p}=0.04)$ (fig. 3B).

There were 511 participants with AD status in the seven trials that compared baclofen to placebo. Baclofen was superior to placebo in reducing heavy drinking days. The SMD of heavy drinking days was $-1.14 \mathrm{~d}(95 \% \mathrm{CI}$ : $-1.95,-0.34 ; \mathrm{p}=0.007)$. Heterogeneity was observed in this outcome $\left(\mathrm{I}^{2}=93.6 \% ; \mathrm{p}<0.001\right)$ (fig. $\left.3 \mathrm{C}\right)$.

Three trials involving a total of 230 patients with $\mathrm{AD}$ reported an outcome of times to relapse $\mathrm{e}^{[29,39,40]}$. The pooled effects from meta-analysis demonstrated that baclofen was not significantly different from placebo in reducing the number of times to relapse (SMD -2.84; $95 \%$ CI $-5.82,014 ; p=0.07)$. There was evidence of heterogeneity among the studies $\left(\mathrm{I}^{2}=98.2 \%, \mathrm{p}<0.0001\right)$ (fig. 3D).

Non-significant differences in craving were observed in baclofen-treated patients compared to placebo ( $\mathrm{SMD}=0.36 ; 95 \% \mathrm{CI}:-0.42,1.14 ; \mathrm{p}=0.37$ ). The results show significant heterogeneity $\left(\mathrm{I}^{2}=91.2 \%\right.$; $\left.<0.001\right)$ (fig. 3E). Moreover, our meta-analysis revealed that the baclofen-treated group did not differ from placebo with regard to the outcome of number of drinking days 


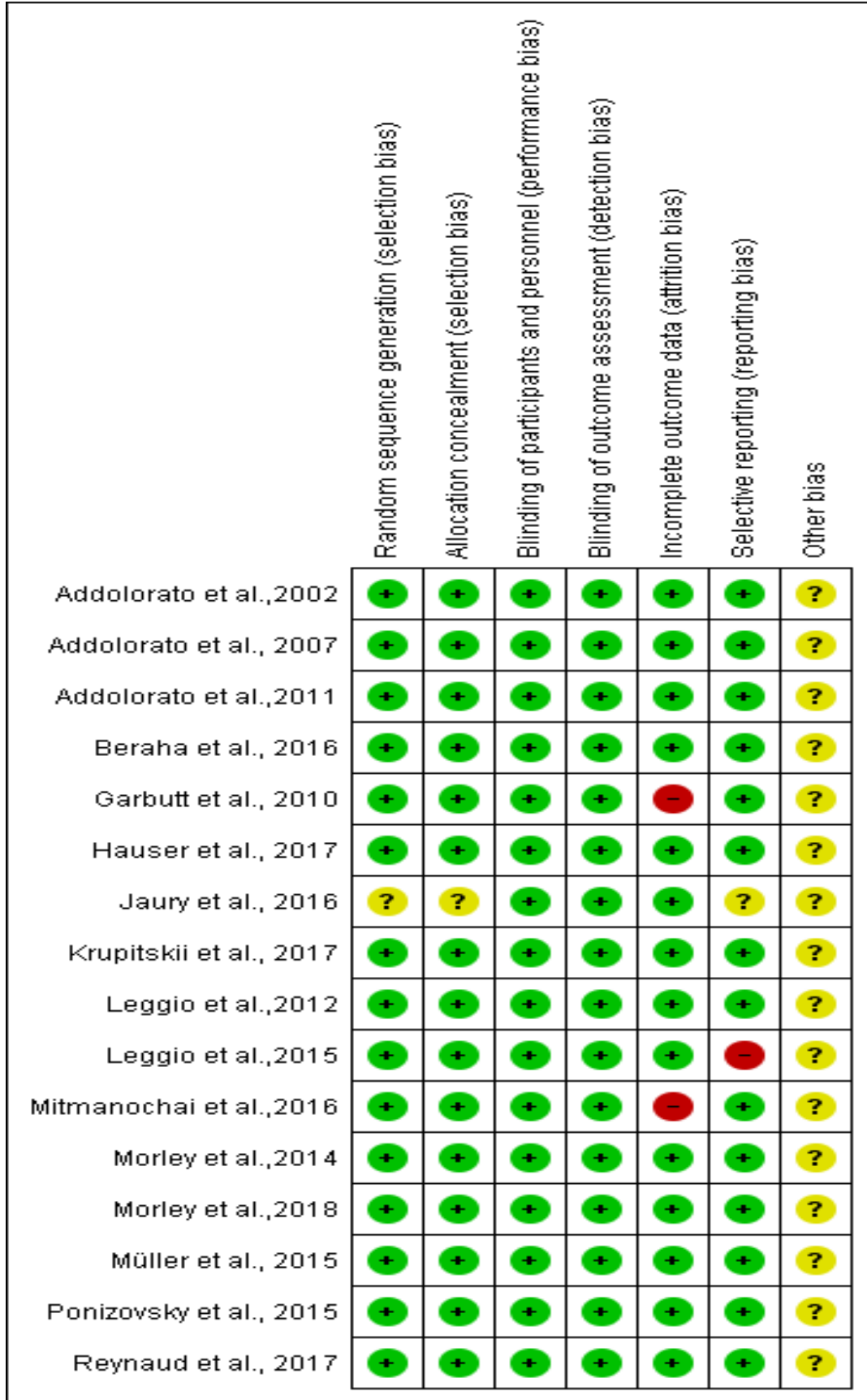

Fig. 2: Risk of bias summary from individual studies (“+”: low risk, “-": high risk and "?”: unclear)

$(\mathrm{SMD}=0.00 ; 95 \% \mathrm{CI}:-0.15,0.16 ; \mathrm{p}=0.56)$. There was no heterogeneity among studies $\left(I^{2}=0.0 \% ; p=0.667\right)$ (fig. 3F).

The pooled analysis indicated that patients treated with baclofen were more likely to experience adverse events related to anticholinergic effects, including dry mouth $(\mathrm{RR}=2.10 ; 95 \% \mathrm{CI}: 1.10,4.03)$. Other adverse effects associated with baclofen administration included fatigue $(\mathrm{RR}=1.51 ; 95 \% \mathrm{CI}: 1.06,2.15)$. Moreover, adverse Central Nervous System (CNS) effects reported by patients included dizziness $(\mathrm{RR}=2.11$; $95 \% \mathrm{CI}: 1.30,3.35)$ and drowsiness $(\mathrm{RR}=1.44 ; 95 \% \mathrm{CI}$ :
$1.08,1.92)$. More details and evidence of heterogeneity for all adverse events are presented in Table 2.

There were 288 participants in six trials that were subjected to liver function tests. The results were not statistically significant in terms of heterogeneity. The pooled results from liver function tests did not show any effect of baclofen on Aspartate Transaminase (AST) or Alanine Transaminase (ALT) levels. The pooled estimate of Weighted Mean Difference (WMD) effects for AST and ALT were $-2.08 \mathrm{U} / 1(95 \% \mathrm{CI}$ -4.20 to $\left.0.05 ; \mathrm{I}^{2}=0.0 \%\right)$ and $0.38 \mathrm{U} / 1(95 \% \mathrm{CI}-4.57$ to $5.34 ; \mathrm{I}^{2}=43 \%$ ), respectively. However, there were 
significant differences in gamma-glutamyl transferase levels between the 156 participants in five trials (WMD $-25.79 \mathrm{U} / 1 ; 95 \% \mathrm{CI}-42.24$ to $-9.33 ; \mathrm{I}^{2}=70 \%$ ).

In this study we utilized the one-study removed approach, where one study is excluded at a time to examine the impact of removal on study results and heterogeneity. Compared to the primary analysis, the one-study removed approach did not indicate any changes in any of the outcomes. Moreover, in the current study the analyses from the random effect model were changed to the fixed effect model in order to determine the sensitivity of each outcome. The fixed effect model of sensitivity analysis revealed different

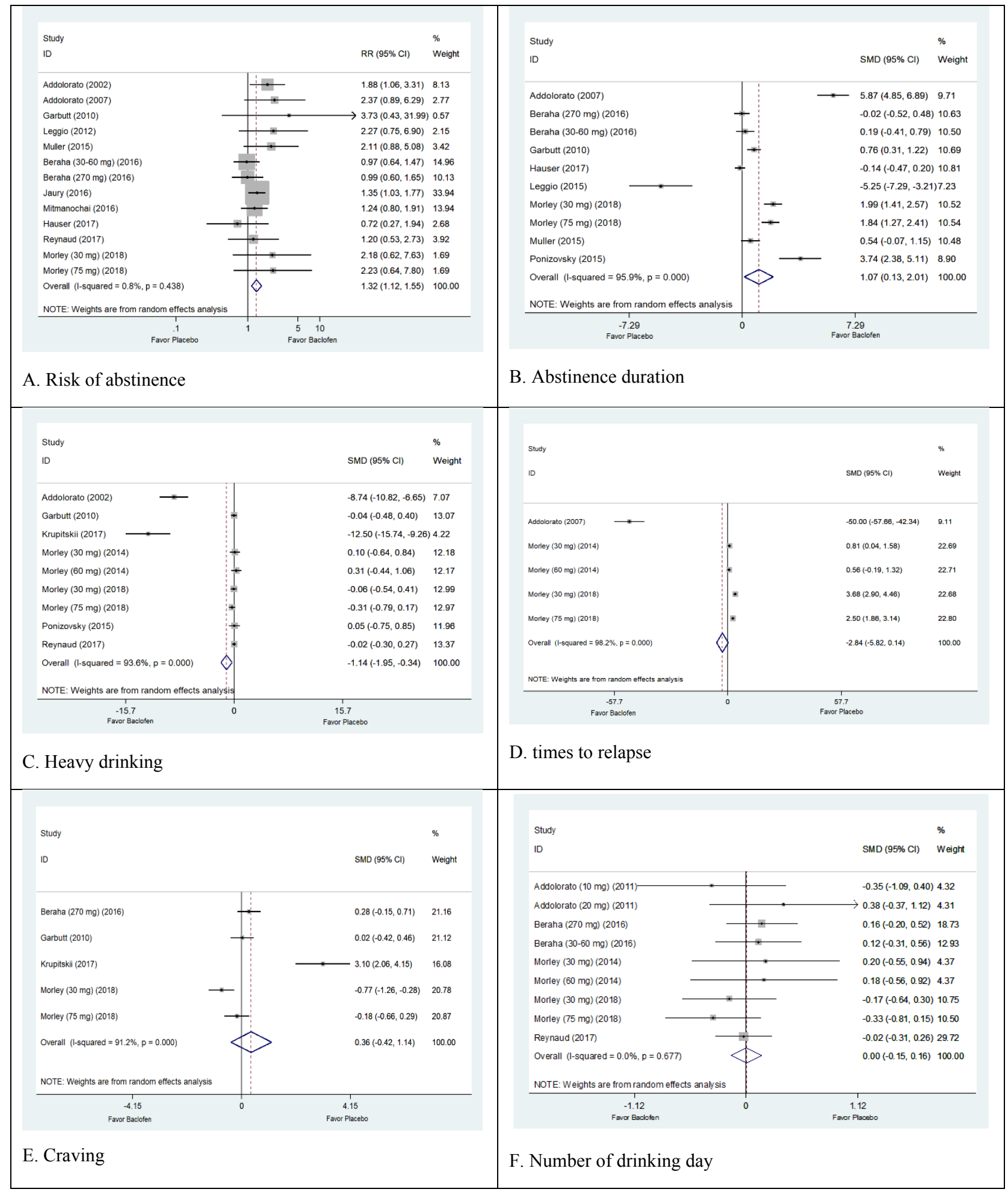

Fig. 3: Meta-analysis of trials testing the efficacy of baclofen versus placebo on primary outcomes; A: Risk of abstinence; B: Abstinence duration; C: Heavy drinking; D: times to relapse; E: Craving and F: Number of drinking day 
findings in heavy drinking days and times to relapse (Table 3).

Subgroup analyses based on the dose of baclofen administered suggested that the clinical efficacy of a low dose of baclofen yielded a statistically significant improvement in risk of abstinence $(\mathrm{RR}=1.68 ; 95 \% \mathrm{CI}$ : $1.07,2.65 ; \mathrm{p}=0.03)$, abstinence duration $(\mathrm{SMD}=2.61$ $\mathrm{d} ; 95 \%$ CI: 0.80, 4.41; $\mathrm{p}=0.005)$, and times to relapse (SMD $=-5.79,95 \% \mathrm{CI}:-9.95,-1.62 ; \mathrm{p}=0.006$, respectively). In terms of the duration of baclofen use, the subgroup analysis found baclofen used for less than $12 \mathrm{w}$ had a benefit on the risk of abstinence $(\mathrm{RR}=1.98$; $95 \%$ CI: 1.30, 3.01; $\mathrm{p}=0.001)$ and abstinence duration (SMD $1.97 \mathrm{~d} ; 95 \%$ CI: 0.17, 3.79; $\mathrm{p}=0.03$, respectively). Moreover, subgroup analysis based on the alcohol consumption level revealed significant improvements in the risk of abstinence ( $\mathrm{RR}=3.04 ; 95 \% \mathrm{CI}: 1.61,5.74$; $\mathrm{p}=0.0006$ ), abstinence duration (SMD $1.98 \mathrm{~d}$ : $95 \% \mathrm{CI}$ : $0.49,3.46 ; \mathrm{p}=0.009$ ) and times to relapse (SMD 1.86; $95 \%$ CI $0.48,3.24 ; \mathrm{p}=0.008$ ) in participants in the very high level alcohol consumption group (Table 4).

Meta-regression was performed to evaluate the association between primary outcomes and the duration of baclofen administration and baclofen dose. The results from random effect meta-regression illustrated that there was no significant association between duration of baclofen use and primary outcomes: risk of abstinence (slope $=-0.14 ; 95 \%$ CI $-1.66,1.39 ; \mathrm{p}=0.85$ ), abstinence duration (slope $=0.40 ; 95 \%$ CI: $-2.80,3.61$; $\mathrm{p}=0.78$ ), heavy drinking days (slope $=0.64 ; 95 \% \mathrm{CI}$ : $-6.95,8.23 ; \mathrm{p}=0.85$ ), times to relapse (slope $=-5.52 ; 95$ $\%$ CI: $-22.92,11.88 ; \mathrm{p}=0.39)$, number of drinking days (slope $=-3.44$; $95 \% \mathrm{CI}:-7.11,0.21 ; \mathrm{p}=0.06$ ). Moreover, baclofen dose was not associated with risk of abstinence (slope $=0.01 ; 95 \%$ CI:-0.18, 0.20; $\mathrm{p}=0.911$ ), abstinence duration (slope $=0.04 ; 95 \% \mathrm{CI}: 0.16,0.25 ; \mathrm{p}=0.62$ ), heavy drinking days (slope $=0.12$; $95 \%$ CI: $-0.77,1.01$; $\mathrm{p}=0.76$ ), times to relapse (slope $=0.89 ; 95 \% \mathrm{CI}-0.80$, $0.98 ; \mathrm{p}=0.77$ ), number of drinking days (slope $=0.04$; 95 \% CI: -0.02, 0.10; $\mathrm{p}=0.17$ ). However, baclofen dose was significantly associated with craving (slope $=-0.05$; $95 \%$ CI: $-0.10,-0.02 ; \mathrm{p}=0.04$ ) (fig. 4).

The publication bias in primary outcomes was investigated using the Egger test. There were no publication bias among risk of abstinence (intercept, 0.90; Standard Error (SE) $=0.52$; 95 \% CI: $-0.23,2.04$; $\mathrm{t}=0.11 ; \mathrm{p}=0.11$ ), abstinence duration (intercept, 4.23; $\mathrm{SE}=3.89 ; 95 \quad \%$ CI:-4.75, 13.22; $\mathrm{t}=1.09 ; \mathrm{p}=0.31)$,

TABLE 2: RESULTS FROM STUDIES REPORTING ADVERSE EFFECTS

\begin{tabular}{|c|c|c|c|c|c|}
\hline $\begin{array}{l}\text { Outcomes } \\
\text { (no. of studies) }\end{array}$ & $\begin{array}{c}\text { No of events/No. of pts in } \\
\text { baclofen groups (\%) }\end{array}$ & $\begin{array}{c}\text { No of events/No. of pts in } \\
\text { placebo groups (\%) }\end{array}$ & $\begin{array}{l}\text { Pooled relative risk } \\
(95 \% \mathrm{Cl})\end{array}$ & $I^{2}$ & $\begin{array}{c}\mathrm{P} \text { for } \\
\text { heterogeneity }\end{array}$ \\
\hline Headaches (9) & $92 / 350$ & $74 / 351$ & $1.29(0.99,1.69)$ & $0.0 \%$ & 0.46 \\
\hline Insomnia (7) & $23 / 282$ & $30 / 286$ & $0.90(0.49,1.67)$ & $10 \%$ & 0.35 \\
\hline Dizziness (6) & $102 / 388$ & $51 / 419$ & $2.11(1.30,3.35)^{*}$ & $36 \%$ & 0.14 \\
\hline Drowsiness (5) & $76 / 264$ & $60 / 309$ & $1.44(1.08,1.92)^{*}$ & $0.0 \%$ & 0.72 \\
\hline Constipation (5) & $30 / 305$ & $28 / 302$ & $1.07(0.66,1.73)$ & $0.0 \%$ & 0.85 \\
\hline Dry mouth (4) & $32 / 287$ & $12 / 309$ & $2.10(1.10,4.03)^{*}$ & $0.0 \%$ & 0.52 \\
\hline Nausea (5) & $36 / 234$ & $36 / 236$ & $1.01(0.60,1.72)$ & $14 \%$ & 0.32 \\
\hline Fatigue (4) & $55 / 218$ & $44 / 262$ & $1.51(1.06,2.15)^{*}$ & 0.0 & 0.59 \\
\hline Muscle pain (4) & $30 / 228$ & $30 / 229$ & $0.99(0.50,1.94)$ & $25 \%$ & 0.26 \\
\hline Skin rash (3) & $15 / 178$ & $13 / 183$ & $1.13(0.36,3.55)$ & $45 \%$ & 0.14 \\
\hline
\end{tabular}

\section{TABLE 3: SENSITIVITY ANALYSIS}

\begin{tabular}{|c|c|c|}
\hline Outcomes & Main analysis & Sensitivity analysis \\
\hline Risk of absti & $\begin{array}{c}\mathrm{RR}=1.32(95 \% \mathrm{Cl}: 1.12,1.55 ; \mathrm{p}=0.0006) ; \\
\mathrm{I}^{2}=0.8 \%\end{array}$ & $\mathrm{RR}=1.53(95 \% \mathrm{Cl}: 1.33,1.77 ; \mathrm{p}<0.00001) ; \mathrm{I}^{2}=0.8$ \\
\hline Abstinence $\mathrm{c}$ & $\begin{array}{c}\mathrm{SMD}=1.07 \mathrm{~d}(95 \% \mathrm{Cl}: 0.13,2.01 ; \mathrm{p}=0.04) ; \mathrm{I}^{2}=95.9 \\
\text { (9) }\end{array}$ & $\begin{array}{c}\mathrm{SMD}=0.97 \mathrm{~d}(95 \% \mathrm{Cl}: 0.78,1.16 ; \mathrm{p}<0.00001): \\
\mathrm{I}^{2}=95.9 \%\end{array}$ \\
\hline Heavy drink & $\begin{array}{c}\mathrm{SMD}=-1.14 \mathrm{~d}(95 \% \mathrm{Cl}:-1.95,-0.34 ; \mathrm{p}=0.007) ; \\
\mathrm{I}^{2}=93.6 \%\end{array}$ & $S M D=-0.14 d(95 \%$ \\
\hline Times $\mathrm{t}$ & $\mathrm{SMD}=-2.79(95 \% \mathrm{Cl}-5.64,0.05 ; \mathrm{p}=0.07) ; \mathrm{I}^{2}=98.1$ & $\mathrm{SMD}=1.78 ;(95 \% \mathrm{Cl}:$ \\
\hline Craving & $\mathrm{SMD}=0.36 ;(95 \% \mathrm{Cl}:-0.42,1.14 ; \mathrm{p}=0.37) ; \mathrm{I}^{2}=91.2$ & $\mathrm{SMD}=0.02 ;\left(\begin{array}{c}95 \% \mathrm{Cl}:-0.21,0 \\
\%\end{array}\right.$ \\
\hline Number of drinking days & $\begin{array}{c}\mathrm{SMD}=0.00(95 \% \mathrm{Cl}:-0.15,0.16 ; \mathrm{p}=0.56) ; \\
\mathrm{I}^{2}=0.0 \%\end{array}$ & $\begin{array}{c}S M D=-0.01(95 \% \mathrm{Cl}:-0.17,0.14 ; \mathrm{p}=0.88) ; \\
\mathrm{I}^{2}=0.0 \%\end{array}$ \\
\hline
\end{tabular}




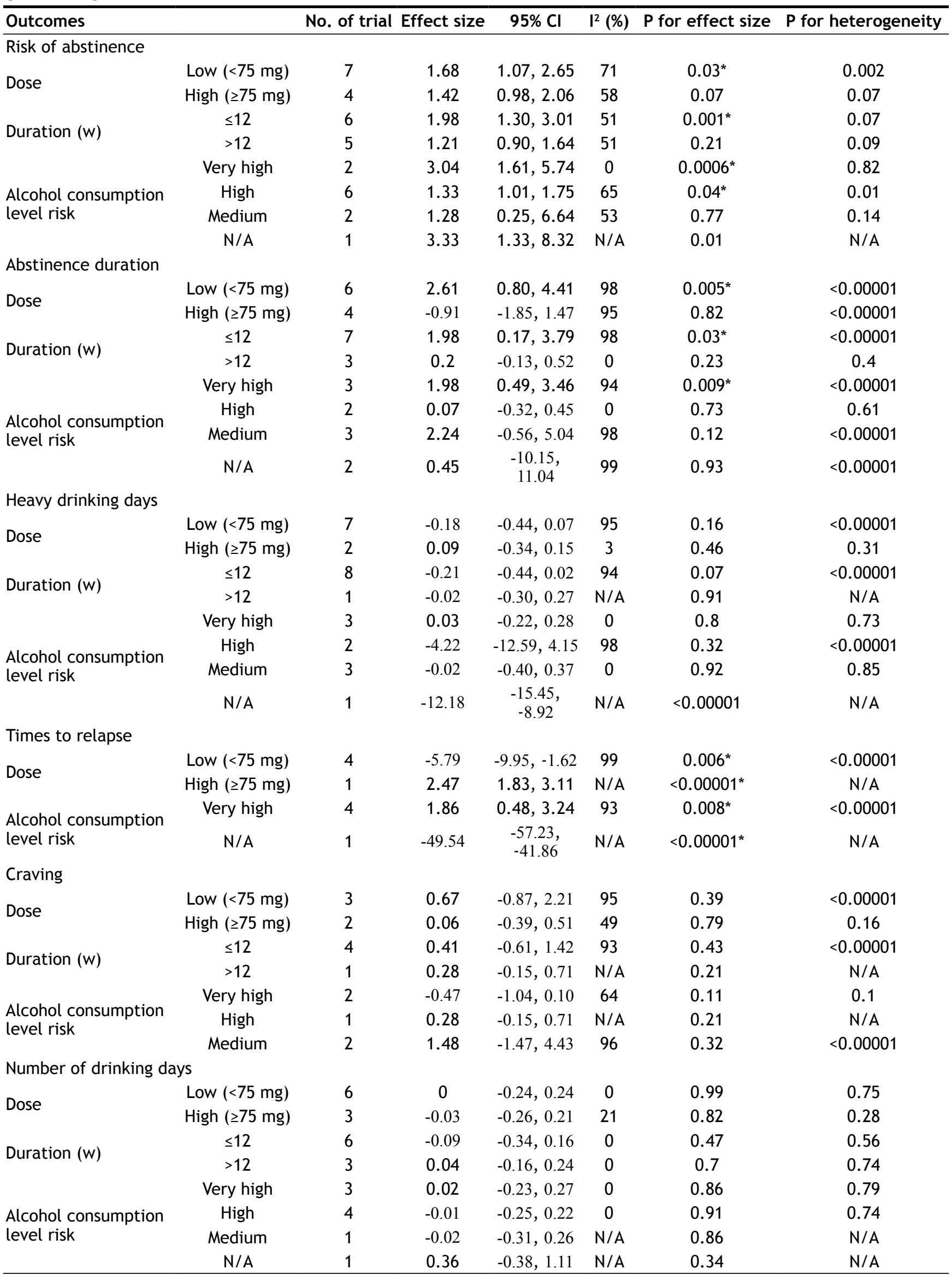

Note: N/A, Not available; g/d, gram per d; mg, milligram 
heavy drinking days (intercept, 1.18; $\mathrm{SE}=1.88 ; 95$ $\%$ CI: $-0.23,2.39 ; \mathrm{t}=2.32 ; \mathrm{p}=0.053)$, times to relapse (intercept, 13.74; $\mathrm{SE}=7.31 ; 95 \% \mathrm{CI}:-17.74,45.23$; $\mathrm{t}=1.88 ; \mathrm{p}=0.25$ ), craving (intercept, 9.35; $\mathrm{SE}=4.35$; $95 \%$ CI: $-4.49,23.19 ; \mathrm{t}=2.15 ; \mathrm{p}=0.12)$ and number of drinking day (intercept, 0.15; SE $=0.89 ; 95 \% \mathrm{CI}$ : $-1.95,2.26 ; t=0.17 ; p=0.87)$. Funnel plots were used to investigate the publication bias for all outcomes. The results indicated no publication bias (fig. 5).

This meta-analysis represents an updated study that included 16 high quality RCTs. It aimed to investigate a wide range of outcomes of baclofen used to treat AD. The significant primary and secondary outcomes

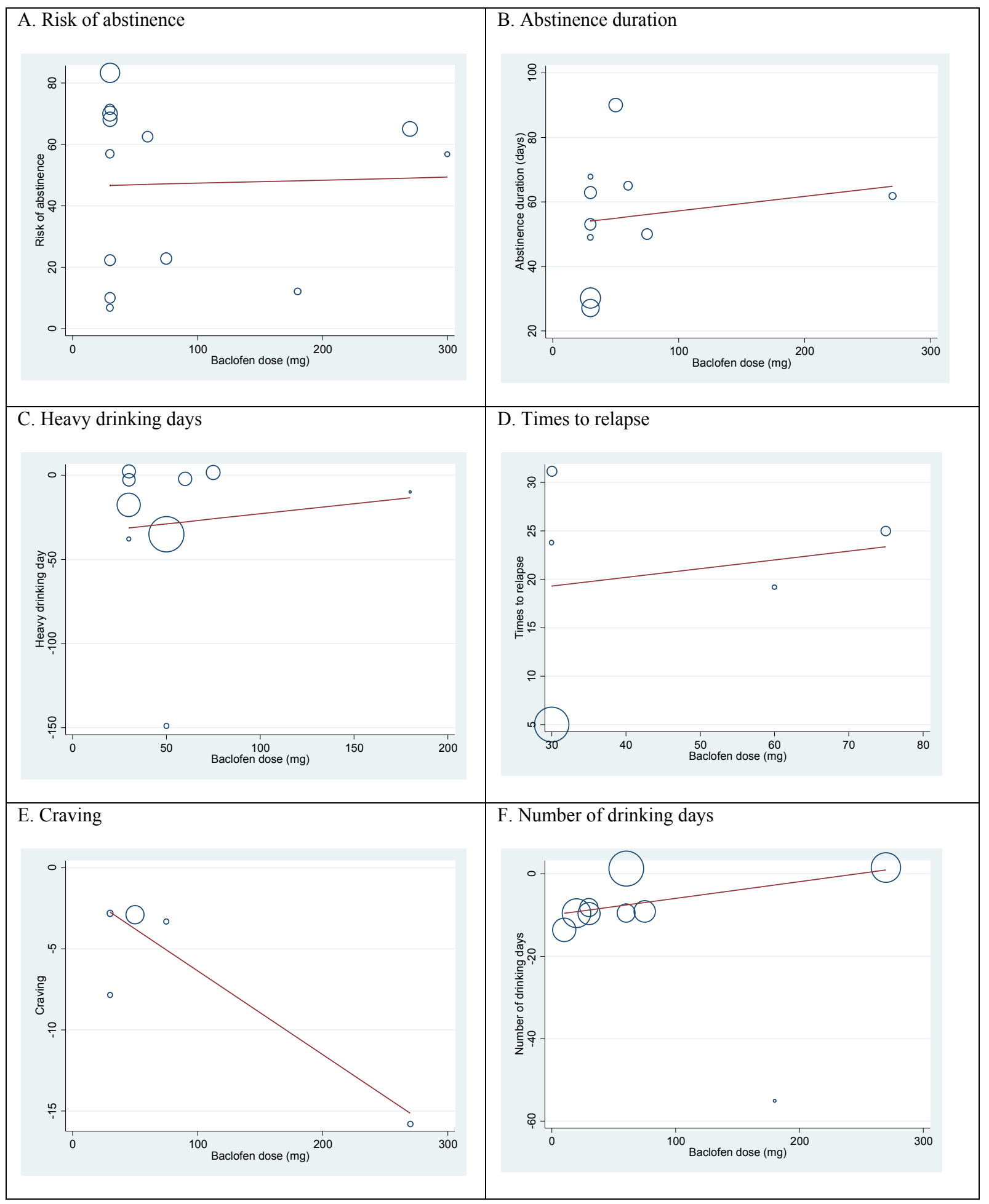

Fig. 4: Bubble-plot for Meta-regression. Meta-regression analysis showed that the association between baclofen dose and primary outcomes. 


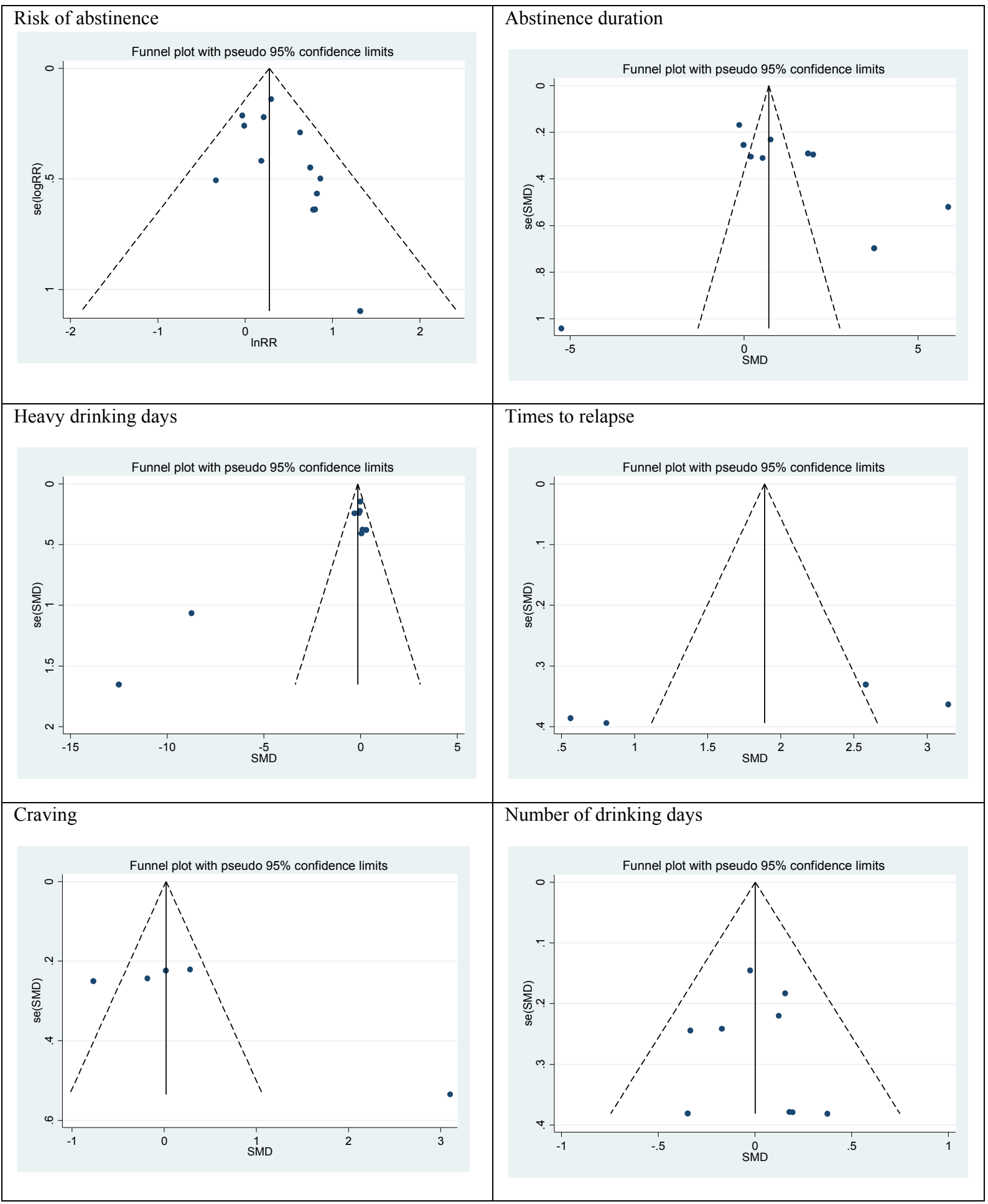

Fig. 5: Funnel plot detailing publication bias

as well as strengths and limitations of this study are discussed below.

Our findings agree with the previous systematic review and meta-analysis ${ }^{[17]}$ which demonstrated that, compared with placebo, baclofen increased the risk of abstinence (Odds Ratio $(\mathrm{OR})=2.67,95 \%$ CI: 1.03-6.93). However, the meta-analysis by Bschor et al. ${ }^{[15]}$ found no effect of baclofen on abstinence outcomes ( $\mathrm{SMD}=0.204$,
95 \% CI: -0.079-0.487). Nonetheless, our findings were drawn from a larger sample size and included more trials and thus should be considered as more reliable. The results from subgroup analysis suggest that lowdose baclofen treatment is more effective than highdose baclofen in increasing the risk of abstinence. However, meta-regression failed to demonstrate an association of baclofen dose with the risk of abstinence. This result suggests that the clinical use of low-dose 
baclofen might be adequate for treatment of $\mathrm{AD}$. Currently, acamprosate (a licensed pharmacotherapy) is the recommended first-line therapy for $\mathrm{AD}$. A metaanalysis of 19 RCTs reported that the efficacy of acamprosate with regard to the risk of abstinence at 3 mo (12 w) was RR=1.33 (95 \% CI: $1.20-1.47)^{[44]}$. Our study found that the efficacy of baclofen on the risk of abstinence was similar to acamprosate. These results suggest that in the future, baclofen might be considered for use in daily clinical practice.

Our meta-analysis revealed that baclofen significantly increased abstinence duration by approximately $1.07 \mathrm{~d}(95 \% \mathrm{CI}: 0.13,2.01)$, which conflicts with the conclusions derived from previous meta-analyses, where non-significant increases in abstinence duration were reported ${ }^{[16,17]}$. While our subgroup analysis showed that low-dose baclofen administered with a short duration $(\leq 12 \mathrm{w})$ resulted in a significantly longer duration of abstinence, the meta-regression confirmed that neither dose nor duration had an association with abstinence duration. Based on data from nine studies, baclofen administration significantly reduced heavy drinking days by $1.14 \mathrm{~d}(95 \% \mathrm{CI}:-1.95,-0.34)$, which conflicts with conclusions from the study by Rose and Jones. Our subgroup analysis and meta-regression revealed similar results to that of abstinence duration. The effects of baclofen on these outcomes were varied, as confirmed using a number of methodological approaches. It should be noted that heterogeneity was observed among the pooled data. Therefore, we recommend additional randomized controlled trials in order to confirm this finding.

Baclofen treatment did not alter the times to relapse or craving. However, the meta-regression analysis did reveal an association of baclofen dose with craving. Reduction of craving is a complex mechanism that is dependent on the dysregulation of various receptors including dopamine and opioid (reward effects), GABA and glutamate (relief effects) and serotonin (obsessive effects). The results on craving are consistent with a previous meta-analysis ${ }^{[17]}$, in which the authors suggested that baclofen may have caused a reduction of craving in those at risk for high levels of alcohol consumption. We performed subgroup analysis to differentiate craving from the risk of high levels of alcohol consumption. Results from the subgroup analysis did not differ from the main analysis.

In terms of AEs, the pooled results demonstrated that participants treated with baclofen were likely to experience $\mathrm{AE}$ related to anticholinergic activity (dry mouth). This adverse effect may have been caused by an anticholinergic effect of baclofen ${ }^{[45]}$. Moreover, adverse CNS effects found in the baclofen-treated group included dizziness and drowsiness, likely occurring as a consequence of GABA-B receptor activation ${ }^{[10]}$. Furthermore, patients in the baclofen-treated group experienced a higher incidence of fatigue compared to the control group. The precise mechanism underlying baclofen's effect on fatigue is not fully understood. One possible mechanism may be baclofen-mediated inhibition of both monosynaptic and polysynaptic reflexes at the level of the spinal cord. Moreover, since baclofen inhibits GABAergic neurotransmission, it may activate GABA-B receptors, resulting in muscle relaxation and decreased muscle force ${ }^{[46]}$.

Our meta-analysis included effects on liver function while the previous meta-analyses did not ${ }^{[15,17]}$. We found that baclofen had no significant effect on liver function tests. These findings suggest that baclofen may represent a safer treatment option for $\mathrm{AD}$ patients who are at risk for impaired liver function.

There were four major strengths of our meta-analysis. First, we searched relevant studies in international and Thai databases as well as unpublished studies. Second, this study represents an updated meta-analysis that included 16 high quality RCTs (Jadad's Scale>3) that had a low risk of bias. Third, we performed subgroup analysis and meta-regression to examine the impact of variables on primary outcomes. Fourth, we included $\mathrm{AE}$ data, whereas the previous systematic reviews and meta-analyse ${ }^{[15,17]}$ only presented descriptive data on $\mathrm{AE}$, without pooling by meta-analysis. AE pooling was performed in our meta-analysis.

Factors that could potentially limit the strength of our meta-analysis includes variability in the dose of baclofen and the duration of treatment across and among included trials, inclusion of only RCTs that compared baclofen and placebo, but not baclofen compared with other drugs used in patients with $\mathrm{AD}$, most of the included trials did not report disease severity, cooccurring disorders, or contaminant medication and an abstinence day difference of one day may be statistically significant but not clinically significant.

Our study showed that baclofen administration to patients with $\mathrm{AD}$ is associated with better outcomes in risk of abstinence, abstinence duration, and the number of heavy drinking days. Based on current evidence, baclofen is safe in patients with AD. Moreover, large well-designed studies that compared with the first-line therapy are required to confirm these conclusions. 


\section{Acknowledgements:}

This research project was financially supported by Mahasarakham University (Fast Track 2021).

\section{Conflict of interests:}

The authors declare that they have no conflict of interest.

\section{REFERENCES}

1. Alcohol. WHO;2018.

2. Rehm J, Gmel Sr GE, Gmel G, Hasan OS, Imtiaz S, Popova $\mathrm{S}$, et al. The relationship between different dimensions of alcohol use and the burden of disease-an update. Addiction 2017;112(6):968-1001.

3. Hasin DS, O'brien CP, Auriacombe M, Borges G, Bucholz $\mathrm{K}$, Budney A, et al. DSM-5 criteria for substance use disorders: recommendations and rationale. Am J Psychiatry 2013;170(8):834-51.

4. Shield KD, Parry C, Rehm J. Chronic diseases and conditions related to alcohol use. Alcohol research: current reviews. 2014;35(2):155-73.

5. Schwarzinger M, Thiébaut SP, Baillot S, Mallet V, Rehm J. Alcohol use disorders and associated chronic disease-a national retrospective cohort study from France. BMC public health. 2018 Dec;18(1):1-9.

6. Rehm J, Shield KD, Gmel G, Rehm MX, Frick U. Modeling the impact of alcohol dependence on mortality burden and the effect of available treatment interventions in the European Union. Eur Neuropsychopharmacol 2013;23(2):89-97.

7. Global status report on alcohol and health 2018. World Health Organization; 2019.

8. Rehm J, Imtiaz S. A narrative review of alcohol consumption as a risk factor for global burden of disease. Subst Abuse Treat Prev Policy 2016;11(1):1-2.

9. Morikawa H, Morrisett RA. Ethanol action on dopaminergic neurons in the ventral tegmental area: interaction with intrinsic ion channels and neurotransmitter inputs. Int Rev Neurobiol 2010;91:235-88.

10. Franck J, Jayaram-Lindström N. Pharmacotherapy for alcohol dependence: Status of current treatments . Curr Opin Neurobiol 2013;23(4):692-9.

11. Colombo G, Serra S, Vacca G, Gessa GL, Carai MA. Suppression by baclofen of the stimulation of alcohol intake induced by morphine and WIN 55,212-2 in alcohol-preferring rats . Eur J Pharmacol 2004;492(2-3):189-93.

12. Liu J, Wang LN. Baclofen for alcohol withdrawal. Cochrane Database Systematic Rev 2017;8:CD008502.

13. Johnson BA. Recent advances in the development of treatments for alcohol and cocaine dependence. CNS Drugs 2005;19(10):873-96.

14. Brennan JL, Leung JG, Gagliardi JP, Rivelli SK, Muzyk AJ. Clinical effectiveness of baclofen for the treatment of alcohol dependence: A review. Clin Pharmacol 2013;5:99.

15. Bschor T, Henssler J, Müller M, Baethge C. Baclofen for alcohol use disorder: A systematic meta-analysis. Acta Psychiatr Scand 2018;138(3):232-42.

16. Pierce M, Sutterland A, Beraha EM, Morley K, van den Brink W. Efficacy, tolerability, and safety of lowdose and high-dose baclofen in the treatment of alcohol dependence: a systematic review and meta-analysis.
Eur Neuropsychopharmacol 2018;28(7):795-806.

17. Rose AK, Jones A. Baclofen: its effectiveness in reducing harmful drinking, craving, and negative mood: A meta-analysis. Addiction 2018;113(8):1396-406.

18. Moher D, Liberati A, Tetzlaff J, Altman DG, PRISMA Group*. Preferred reporting items for systematic reviews and metaanalyses: the PRISMA statement. PLoS Med 2009;151(4): 264-9.

19. Jadad AR, Moore RA, Carroll D, Jenkinson C, Reynolds DJ, Gavaghan DJ, et al. Assessing the quality of reports of randomized clinical trials: is blinding necessary? Control Clin Trials 1996;17(1):1-12.

20. Higgins JP, Thomas J, Chandler J, Cumpston M, Li T, Page MJ, et al. Cochrane handbook for systematic reviews of interventions. John Wiley \& Sons; 2019.

21. Higgins JP, Thompson SG, Deeks JJ, Altman DG. Measuring inconsistency in meta-analyses. Bmj 2003;327(7414):557-60.

22. Egger M, Smith GD, Schneider M, Minder C. Bias in meta-analysis detected by a simple, graphical test. Bmj 1997;315(7109):629-34.

23. Peters JL, Sutton AJ, Jones DR, Abrams KR, Rushton L. Comparison of two methods to detect publication bias in meta-analysis Jama 2006;295(6):676-80.

24. DerSimonian R, Laird N. Meta-analysis in clinical trials. ontrol Clin Trials 1986;7(3):177-88.

25. Borenstein M, Hedges LV, Higgins JP, Rothstein HR. Fixedeffect versus random-effects models. Introduction to Metaanalysis 2009;77:85.

26. Sahebkar A. Are curcuminoids effective C-reactive proteinlowering agents in clinical practice? Evidence from a metaanalysis. Phytother Res 2014;28(5):633-42.

27. Mann K, Aubin HJ, Witkiewitz K. Reduced drinking in alcohol dependence treatment, what is the evidence? Eur Addict Res 2017;23(5):219-30.

28. Addolorato G, Caputo F, Capristo E, Domenicali M, Bernardi $\mathrm{M}$, Janiri L, et al. Baclofen efficacy in reducing alcohol craving and intake: A preliminary double-blind randomized controlled study . Alcohol Alcohol 2002;37(5):504-8.

29. Addolorato G, Leggio L, Ferrulli A, Cardone S, Vonghia L, Mirijello A, et al. Effectiveness and safety of baclofen for maintenance of alcohol abstinence in alcohol-dependent patients with liver cirrhosis: randomised, double-blind controlled study . Lancet 2007;370(9603):1915-22.

30. Addolorato G, Leggio L, Ferrulli A, Cardone S, Bedogni G, Caputo F, et al. Dose-response effect of baclofen in reducing daily alcohol intake in alcohol dependence: Secondary analysis of a randomized, double-blind, placebo-controlled trial. Alcohol Alcohol 2011;46(3):312-7.

31. Beraha EM, Salemink E, Goudriaan AE, Bakker A, de Jong D, Smits $\mathrm{N}$, et al. Efficacy and safety of highdose baclofen for the treatment of alcohol dependence: A multicentre, randomised, double-blind controlled trial. Eur Neuropsychopharmacol 2016;26(12):1950-9.

32. Garbutt JC, Kampov-Polevoy AB, Gallop R, Kalka-Juhl L, Flannery BA. Efficacy and safety of baclofen for alcohol dependence: a randomized, double-blind, placebo-controlled trial. Alcohol Clin Exp Res 2010;34(11):1849-57.

33. Hauser P, Fuller B, Ho SB, Thuras P, Kern S, Dieperink E. The safety and efficacy of baclofen to reduce alcohol use in veterans with chronic hepatitis $\mathrm{C}$ : A randomized controlled trial. Addiction 2017;112(7):1173-83.

34. Jaury P. Bacloville presentation; 2016.

35. Krupitskii EM, Rybakova KV, Kiselev AS, Alekseeva YV, 
Berntsev VA, Chekhlatyi EI, et al. Efficacy and safety of the use of baclofen in the treatment of alcohol dependent (a double-blind, randomized, placebo-controlled pilot study) . Neurosci Behav Physiol 2017;47(2):153-62.

36. Leggio L, Ferrulli A, Zambon A, Caputo F, Kenna GA, Swift $\mathrm{RM}$, et al. Baclofen promotes alcohol abstinence in alcohol dependent cirrhotic patients with hepatitis $\mathrm{C}$ virus (HCV) infection. Addicti Behav 2012;37(4):561-4.

37. Leggio L, Zywiak WH, Edwards SM, Tidey JW, Swift RM, Kenna GA. A preliminary double-blind, placebo-controlled randomized study of baclofen effects in alcoholic smokers. Psychopharmacol 2015;232(1):233-43.

38. Mitmanochai W, Wittayanookulluk A, Niwatananun W. Efficacy and Safety for Maintenance of Alcohol Abstinence in Alcohol-Dependent Patients, Thanyarak Chiang Mai Hospital. Bull Suanprung 2016;32:66-83.

39. Morley KC, Baillie A, Leung S, Addolorato GI, Leggio L, Haber P. Baclofen for the treatment of alcohol dependence and possible role of comorbid anxiety. Alcohol Alcohol 2014;49(6):654-60.

40. Morley KC, Baillie A, Fraser I, Furneaux-Bate A, Dore $\mathrm{G}$, Roberts $\mathrm{M}$, et al. Baclofen in the treatment of alcohol dependence with or without liver disease: Multisite, randomised, double-blind, placebo-controlled trial. $\mathrm{Br} \mathrm{J}$
Psychiatry 2018;212(6):362-9.

41. Müller CA, Geisel O, Pelz P, Higl V, Krüger J, Stickel A, et al. High-dose baclofen for the treatment of alcohol dependence (BACLAD study): A randomized, placebo-controlled trial . Eur Neuropsychopharmacol 2015;25(8):1167-77.

42. Reynaud M, Aubin HJ, Trinquet F, Zakine B, Dano C, Dematteis $\mathrm{M}$, et al. A randomized, placebo-controlled study of high-dose baclofen in alcohol-dependent patients: the ALPADIR study. Alcohol Alcohol 2017;52(4):439-46.

43. Ponizovsky AM, Rosca P, Aronovich E, Weizman A, Grinshpoon A. Baclofen as add-on to standard psychosocial treatment for alcohol dependence: a randomized, double-blind, placebo-controlled trial with 1 year follow-up. J Subst Abuse Treat 2015;52:24-30.

44. Mann K, Lehert P, Morgan MY. The efficacy of acamprosate in the maintenance of abstinence in alcohol-dependent individuals: Results of a meta-analysis. Alcohol Clin Exp Res 2004;28(1):51-63.

45. Stroup TS, Gray N. Management of common adverse effects of antipsychotic medications. World Psychiatry 2018;17(3):34156.

46. Mohammed I, Hussain A. Intrathecal baclofen withdrawal syndrome-a life-threatening complication of baclofen pump: A case report. BMC Clin Pharmacol 2004;4(1):1-5. 